\title{
Modelling of roughness effect on hydrogen permeation in a low carbon steel
}

\author{
J.A. Carreño", I. Uribe" and J.C. Carrillo"*
}

\begin{abstract}
A model is presented to evaluate the effect of the roughness and the profile of concentration of hydrogen in a low carbon steel. The model takes advantage of the Fick's Second Law, to predict the transport of hydrogen in the steel. The problem is treated as a variational one and its space solution is made numerically by means of the Finite Elements Method, while the temporal equation is solved via the Finite Differences Method, in order to determine the concentration profiles of Hydrogen in the steel and to quantify the roughness effect. Simultaneously, bipotentiostatic hydrogen permeation test were performed to evaluate the coefficient of mass transfer.
\end{abstract}

Keywords Adsorption. Diffusion. Hydrogen. Permeation. Roughness. Solubility.

\section{Modelado del efecto de rugosidad en la permeación de hidrógeno en un acero de bajo carbono}

Resumen

El presente trabajo modela el efecto de la rugosidad y el perfil de concentración de hidrógeno en un acero, tomando como punto de partida la segunda ley de Fick para explicar el transporte de hidrógeno en el acero. El problema se trata como un problema variacional y su solución espacial se hace numéricamente por el Método de Elementos Finitos, mientras que la temporal por el Método de Diferencias Finitas, siendo estas las herramientas utilizadas para determinar los perfiles de concentración y cuantificar el efecto superficial presentado en este tipo de fenómeno. Además, a partir de la teoría se obtienen ecuaciones algebraicas que determinan el efecto que tiene la preparación superficial y el coeficiente de transferencia de masa con la permeación y concentración de hidrógeno en el acero.

Palabras clave Absorción. Difusión. Hidrógeno. Permeabilidad. Rugosidad. Solubilidad.

\section{INTRODUCTION}

It has been known for many years that steel in pipes, pressure vessels or other components in contact with hydrogen can suffer problems of attack or embrittlement. Degradation of properties and loss of serviceability may be given in terms of microstructural changes, embrittlement, sulphide stress cracking, loss of strength and toughness, and environmentally assisted cracking. Since hydrogen can induce many types of damage in engineering materials, many different explanations have been proposed for the hydrogen embrittlement. One such explanation is the General Theory of Transport Models ${ }^{[1]}$ which considers that if hydrogen is the agent of the nucleation of internal cracks in the material, the hydrogen must be transported through the solution, adsorbed, absorbed, transported internally by diffusion or dislocations motion, and then must contribute to crack nucleation and crack propagation. Any of them, could be the controlling mechanics of the diffusion rate.

Permeation measurements yield definitive information on both hydrogen solubility and transport. However, mathematical models have been developed in order to explain the diffusion of the hydrogen in the steels, based on the of Fick's First and Second Laws, from which concentration profiles and diffusion coefficients of hydrogen were obtained in the steel. However, hydrogen damage problems might not be explained with these equations.

$\left(^{*}\right)$ Escuela de Ingeniería Metalúrgica y Ciencia de Materiales. Grupo de Investigaciones en Corrosión. Línea de Hidrógeno en Materiales.

$\left.{ }^{(* *}\right)$ Escuela de Matemáticas. Universidad Industrial de Santander. Apartado Aéreo 678. Bucaramanga, COLOMBIA. 
In $1963 \mathrm{Mc} \mathrm{Nabb}$ and Foster ${ }^{[2]}$ proposed to the scientific community a mathematical model that explained the diffusion hydrogen in the steels, treated with saturated traps. This model was conformed by a system of partial differential equations, where the parameters are the respective transition probabilities for hydrogen transport from trap to lattice site; all the phenomenon of transfer of mass was taken at room temperature, but without experimental validation.

In 1975 Caskey and Pillinger ${ }^{[3]}$ took as a base the theory of Mc Nabb and Foster; they developed techniques for numerical solutions by means of the Finite Differences Method to solve the model, obtaining simulated curves of the permeation of hydrogen in any material. It was only until 1991 when Makhlouf ${ }^{[4]}$ presented a numeric solution for the model of Mc Nabb and Foster. He introduced the superficial effect for the first time on the permeation of hydrogen, quantified by a constant similar to the convection coefficient in heat transfer. Beginning with the work of Makhlouf it was shown the importance of the relationship that the models should have with the experimental works, because in the two previously explained models there was not any relationship.

In 1994 a mathematical model developed by Amey, Michal and Payer ${ }^{[5]}$ is presented. That model brokes the outlines introduced by Mc Nabb and Foster, and the effect of the trapping of hydrogen is rejected, making special emphasis in the superficial effect, because the hydrogen is generated electrochemically. This model is applicable to a great number of charging conditions, and it is based on experimental data, determining this way the behaviour of the hydrogen in the low carbon steels, under several load cycles. They consider the superficial constants as a deviation of the electrochemical behaviour and the solubility of the hydrogen in the steel, taking as a base the Nerst's Law and the Sievert's Law, respectively.

In 1983 Watanabe and Murakamy ${ }^{[6]}$ developed a model by the Method of Finite Elements to determine the distribution of hydrogen in steady state, in the steel of a reactor, under operation conditions.

The development of this study tries to understand the diffusion and quantification phenomena of the hydrogen existing in the thickness of the steel plates and the influence of the roughness in the permeability and the profiles of concentration of hydrogen in the material.

\section{MATHEMATICAL DEVELOPING}

In the General Theory of the Models of Transport it is initially postulated that the diffusion of hydrogen in the steel is one of the decisive steps in the rate controlling of the process of hydrogen damage. The effect of the traps is rejected, considering that the steel is subjected to high concentrations of hydrogen and the small thickness of the plate, as was mentioned by Mc Nabb and Foster. Figure 1 shows the stages of hydrogen transport through a steel plate for a system which has an electrochemical source of hydrogen. The boundary conditions are affected by the superficial conditions of the metal.

It is considered an isotherm system composed by a metallic plate of known chemical composition and thickness, whose lateral surfaces separate two well known electrolytic solutions. The main variable of this study is the concentration of atomic hydrogen in the material. The Hydrogen transport by simple diffusion is governed by Fick's Second Law $^{[7]}$, as expressed in the equation (1), and the flow direction of hydrogen inside the metallic plate is perpendicular to the cross area of the plate. Perpendicular flows to the sample thickness or in other directions are not considered. So,

$$
D \frac{\partial^{2} \mathrm{C}(z, t)}{\partial z^{2}}+\frac{\partial C(z, t)}{\partial t}=0 \text { in } \Omega
$$

where the atomic hydrogen $C$ in the steel is dependent on the thickness and on the time $t, D$ is the diffusion coefficient, and $W$ represents the volume of the steel plate. The equation (1) is subjected to the following boundary conditions:

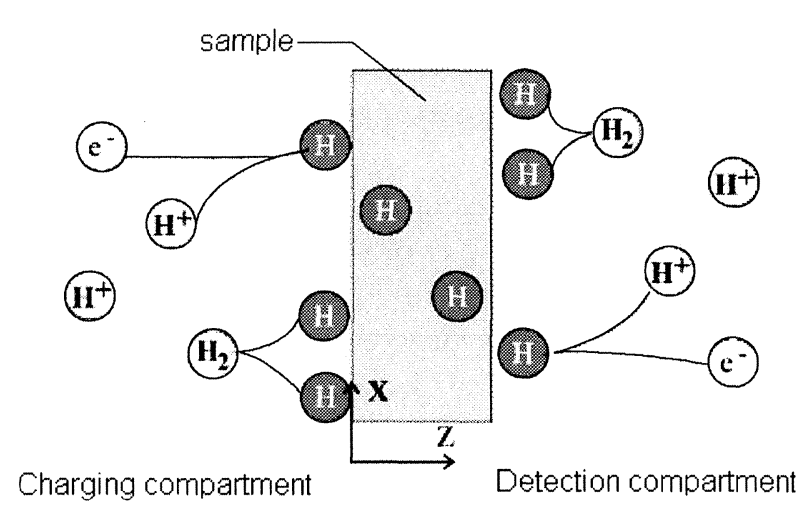

Figure 1. General process of the hydrogen difusión.

Figura 1. Proceso general de la difusión de hdrógeno. 


$$
\begin{aligned}
& -D \frac{\partial C(0, t)}{\partial z}=K_{1}\left(C_{1}-C_{0}\right) \\
& -D \frac{\partial C(L, t)}{\partial z}=K_{2}\left(C_{L}-C_{2}\right)
\end{aligned}
$$

with the initial condition:

$$
C(z, 0)=0
$$

where $C_{1}$ and $C_{2}$ are the concentrations of hydrogen in each one of the available surfaces of the steel for the diffusion, $L$ is the thickness of the metallic plate, and $K_{1}$ and $K_{2}$ are the coefficients of mass transfer in each one of plate surfaces.

Equation (1) possesses a variational form in which the natural conditions of the problem are present; when this form is minimised the obtained function describes the total solution of the problem. By means of the Inverse Problem Method ${ }^{[8]}$, after some steps we obtain:

$$
\begin{aligned}
& I(C)=\frac{1}{2} \int_{\Omega}\left[D\left(\frac{\partial C}{\partial z}\right)^{2}+2 C \frac{\partial C}{\partial t}\right] A(z) d z- \\
& -\frac{1}{2}\left(\left.K_{1}\left(C C_{1}-C^{2}\right) A_{1}\right|_{z=0}+\left.K_{2}\left(C^{2}-C_{2}\right) A_{2}\right|_{z=L}\right)
\end{aligned}
$$

The functional I (C) can be used to analyse the incoming and outcoming of hydrogen in sheets of any material; however, if the same methodology is carried out in the other two dimensions, it can be applied to geometrically more complex pieces and it can be defined in Cartesian coordinates.

As the cross area of the sheet remains constant in the whole specimen, then the area in each one of the surfaces $A_{1}, A_{2}$ and the cross area $A(z)$ are the same and disappear in the expression (5).

After the quadratic functional or variational problem it obtained, we proceed via variational calculus to obtain the minimum of the equation (5). The solution is obtained applying the Finite Elements Method ${ }^{[9]}$. Then we proceed to the discretization of the thickness of the steel plate in several elements, where one of them is taken as representative, using the approaching function (6):

$$
\mathrm{C}_{e}(z, t)=[N(z)] \cdot\{\mathrm{C}(t)\}
$$

where $[N(z)]$ is the vector form function and $\{C(t)\}$ it is the vector column that defines the hydrogen concentration in each node of the element which function of the time.

Equation (5) is replaced in the equation (6), this reformed equation is minimized with regard to the each node concentration described in the vectorial column $\{C(t)\}$, then all elements are assembled and the boundary conditions are replaced, being obtained the problem space solution in the following ordinary differential system of first order equations

$$
\left[k_{1}\right] \cdot\{\mathrm{C}\}+\left[k_{2}\right] \cdot\left\{\frac{\partial \mathrm{C}}{\partial t}\right\}=[P]
$$

where $\left[k_{1}\right],\left[k_{2}\right]$ and $[P]$ are coefficients matrix, obtained by the minimising of the equation (5).

After that the temporary solution of the differential equation (7) is obtained by means of the Finite Differences Method, so that we have the following system of linear equations:

$$
[A]\{C\}_{n+1}=[B]\{C\}_{n}+\{P\}_{n, n+1}
$$

where $[A],[B]$ and $[P]$ are new coefficients matrix obtained starting from the equation (7).

The numeric solve of hydrogen permeation $P$ in the metal, it is obtained by the equation:

$$
P(t)=-D L\left(\frac{C_{n}(t)-C_{n-1}(t)}{l_{e}}\right)
$$

where $n$ is the position of the node in the material.

To determine the concentration of available atomic hydrogen in the entrance and exit surface of the steel, or adsorbed in each one of the surfaces of the metal, it is necessary to quantify the variable $\mathrm{C}_{1}$ and $\mathrm{C}_{2}$ under the boundary conditions, which depend on the electrochemical variables of the system.

Taking into account the chemical equation which takes place in each one of the surfaces,

$$
\mathrm{H}^{+}+e^{-} \leftrightarrow \frac{1}{2} \mathrm{H}_{2}
$$

the expressions that define the Nerst's Law and the Sievert's Law ${ }^{[10]}$ are applied and we obtain:

$$
C_{s}=[H]=S \exp \left(\frac{E_{0}-E}{R T} F-2.303 \mathrm{pH}\right)
$$


where $E$ is the working potential, $E_{0}$ is the standard potential given in Volts, $T$ the temperature, $S$ the solubility, $F$ and $R$ are the constants of Faraday and the ideal gases, respectively.

To obtain the transfer mass coefficient $K$ in each one of the surfaces, it is considered that in the steady state the entrance flow (2) and that of exit (3), together with the flow through the sheet, are the same. Supposing that the concentration $\mathrm{C}_{2}$ is much smaller that of $\mathrm{C}_{1}$, due to the high generation of Hydrogen on this surface, $K_{1}$ and $K_{2}$ are the same because each surface was polished in the same way and they were exposed to the same solution. Then,

$$
\frac{1}{P}=\frac{2}{C_{1} K L}+\frac{1}{C_{1} D}
$$

where $P$ is the permeability.

\section{DISCUSSION}

The experimental system used is based on the Devanathan-Stachurski permeation cell. At first, it was checked the sensitivity of the permeation test to detect different behaviours from different superficial conditions. It has been observed that an increment of the superficial area implies a diminishment of the potential of cathodic polarization, which is associated with an increment of the adsorbed hydrogen concentration.

This effect is reflected in the Hydrogen flux through the plate. The increment in the area will generate a decrease of the cathodic Hydrogen generation potential, just as it is demonstrated in the relationship of Nerst and Sievert (11); the above mentioned makes that the coefficient of mass transfer that measures the rate with which the adsorbed hydrogen is absorbed or vice versa, increases the permeability, as it is observed in (12), and it is reflected in the experimental curves of permeation in figure 2 .

The mass transfer coefficient, $K$, is of great importance because influences the Hydrogen permeation, and this can be obtained experimentally applying the equation (11) and (12). Figure 2 shows the comparison results of the experimental curve, with the simulations and experimental curve.

The effect of the mass transfer coefficient in the concentration profiles was simulated in order to obtain the concentration of hydrogen in the plate. Figure 3 shows the variation of mass transfer coefficient keeping the other parameters constant. In the same way as Amey, it is showed that the increase in the mass transfer coefficient allows that more hydrogen adsorbed is absorbed by the material, and its inverse would be reflected as the impediment that the material has to spread in the steel. As it was shown in the experimental

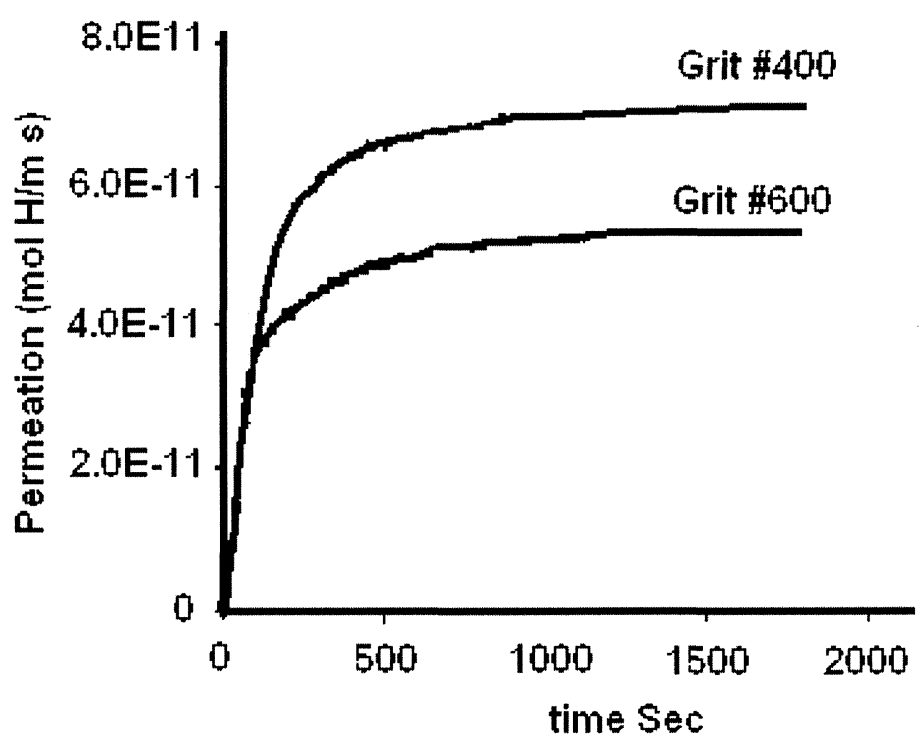

(a)

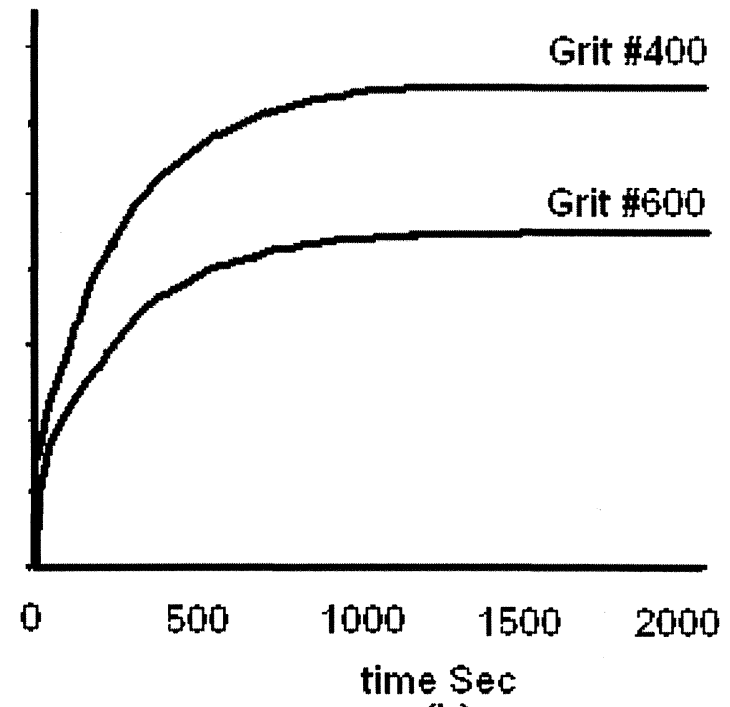

(b)

Figure 2. Hydrogen permeation curves for different grit. (a) Experimental curve and (b) model simulations.

Figura 2. Curvas de permeación de hidrógeno para diferentes rugosidades (a) Curva experimental y (b) Simulaciones. 
Table I. Hydrogen permeation parameters and polarization results. (AISI 1010 steel, solution $0.1 \mathrm{~N}$ of $\mathrm{NaOH}$, Generation Hydrogen Potential of $-1.278 \mathrm{VNHE}$, thickness $0.7 \mathrm{~mm}$, temperature $32{ }^{\circ} \mathrm{C}$, solubility $0.4034 \mathrm{~mol} \mathrm{H} / \mathrm{m}^{3}$, and difusivity $\left.1.7323 \mathrm{E}^{-10} \mathrm{~m}^{2} / \mathrm{s}\right)$

Tabla I. Resultados de parámetros de permeación y polarización. (Acero AISI SAE 1010 en solución $0.1 \mathrm{~N}$ de $\mathrm{NaOH}$ y Potencial de Generación de Hidrógeno - 1.278 V HHE, espesor de $0.7 \mathrm{~mm}$, temperatura de $32{ }^{\circ} \mathrm{C}$, solubilidad de $0.4034 \mathrm{~mol} \mathrm{H} / \mathrm{m}^{3}$, y difusibidad de $1.7323 \mathrm{E}^{-10} \mathrm{~m}^{2} / \mathrm{s}$.)

\begin{tabular}{ccccc}
\hline Grit Paper \# & $\mathrm{E}_{0}(\mathrm{~V}) \mathrm{NHE}$ & $\mathrm{P}(\mathrm{molH} / \mathrm{m} \mathrm{s})$ & $\mathrm{C}_{1}\left(\mathrm{molH} / \mathrm{m}^{3}\right)$ & $\mathrm{K}(\mathrm{m} / \mathrm{s})$ \\
\hline 400 & -0.197 & $6.50 \mathrm{E}^{-11}$ & $4.78 \mathrm{E}^{-4}$ & $1.94 \mathrm{E}^{-12}$ \\
600 & -0.152 & $4.50 \mathrm{E}^{-11}$ & $2.65 \mathrm{E}^{-5}$ & $2.43 \mathrm{E}^{-13}$ \\
\hline
\end{tabular}

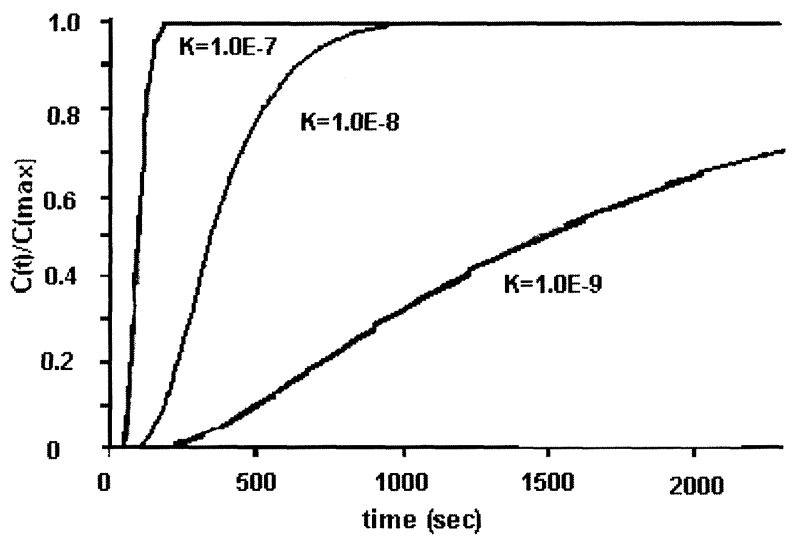

Figure 3. Variation of mass transfer coefficient.

Figura 3. Variación del coeficiente de transferencia de la masa.

analysis, the mass transfer coefficient will be the decisive step in the process, because, as it is shown in figure 4 , the superficial conditions can influence enormously in the process of transport of hydrogen in the material.

Figure 4 illustrates the fact that the incoming hydrogen concentration in the material during the

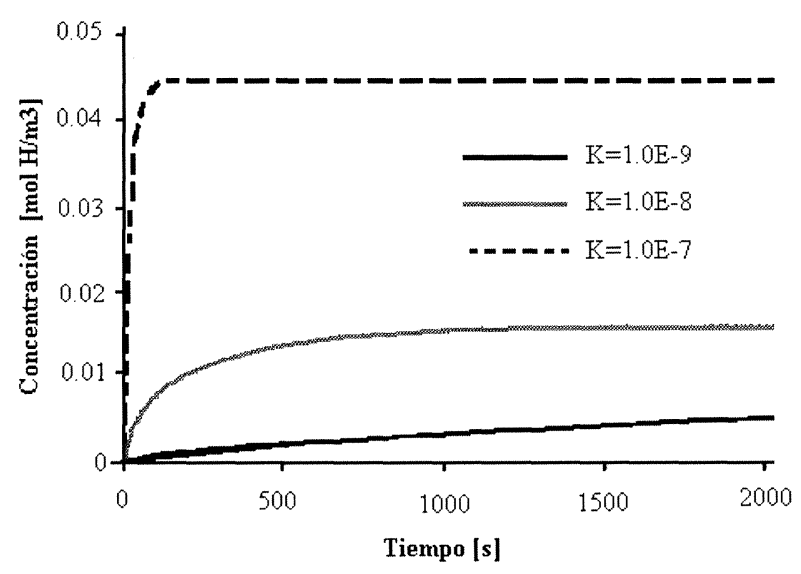

Figure 4. Entry effects.

Figura 4. Efectos de entrada.

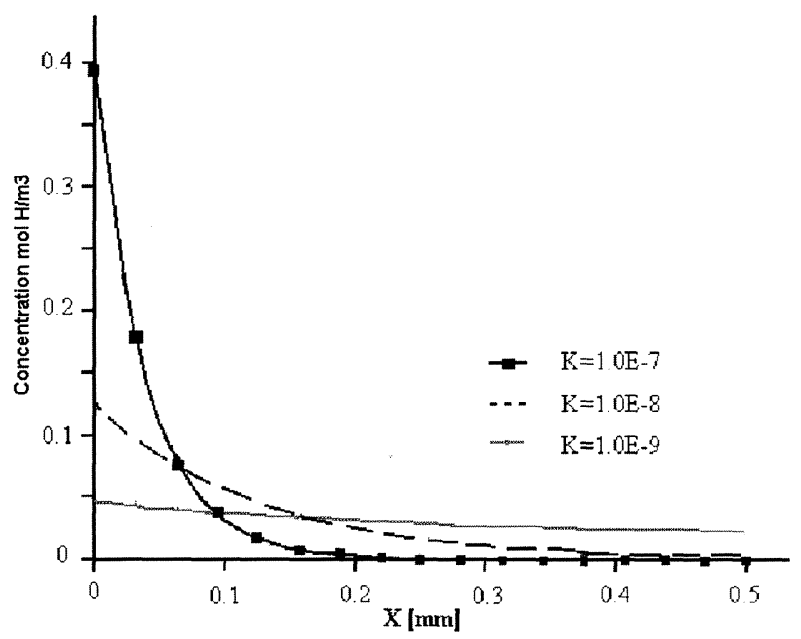

Figure 5. Hydrogen concentration profiles.

Figura 5. Perfiles de concentración de hidrógeno.

process is directly proportional to the transfer mass coefficient. However, it occurs the opposite in the outcoming hydrogen surface, as it observed in the figure 5; with the hydrogen exit concentrations, the increment of the transfer mass coefficient affects in the permeation like an impediment to the hydrogen exit. The above mentioned is observed in the figure 5 , in which the effect is manifested in the decrease of the coefficient $\mathrm{K}$, which acts like a resistance, decreasing the flux and the quantity of hydrogen in the material.

\section{CONCLUSIONS}

The numeric solution to the variational problem of Hydrogen diffusion expressed in the equation (5) was able to predict the profiles of concentration of hydrogen through the thickness of a steel plate, verifying the importance that has the mass transfer coefficient $K$ in the processes of diffusion of hydrogen.

This mass transfer coefficient can be considered as the flux with which the material absorbs the 
adsorbed hydrogen in the surface, that parameter can be the decisive step in the total process of Hydrogen embrittlement. Its implicit variables are the roughness and the potential, which are correlated each other, because it was proved that as the roughness at constant potential is diminished, the permeability of hydrogen in the material decreases.

On the other hand, this work shows that the hydrogen diffusion coefficients obtained in the steady state by the traditional model are not completely exact, and hence the accuracy is not reached in the application of the variational model

\section{Acknowledgements}

This work represents a portion of a thesis of J.A. Carreño submitted to the Metallurgical Engineering degree requirements at the Universidad Industrial de Santander (UIS). The authors would like to thank the Group of Corrosion of the UIS, for their assistance. Special thanks are also due to professors Custodio Vásquez and to Bernardo Mayorga for their helpful discussions and to Pablo E. Valadado de Miranda, professor of the Laboratoy of Muchigan of the COPPE-UFRI, for this valuable contributions to the realization of this investigation.

\section{REFERENCES}

[1] R. Gibala, Hydrogen Embrittlement and Stress Corrosion Cracking, American Society for Metals, Metals Park, OH., 1995, p. 324.

[2] A. MC NABB and P.K. Foster, Trans. TMS-AIME 227 (1963) 618.

[3] G.R. Caskey and W.L. Pillinger, Metal. Trans. A. 6 (1975) 467-476.

[4] M. Makhlouf and R. Sisson, Metal. Trans. A. 22 (1991) 1001-1006.

[5] S.L. Amey, G.M. Michal and J.H. PAyer, Metal. Trans. A. 25 (1994) 723-732.

[6] J. Watanabe and Y. Murakamy, Startup and Shutdown Procedures of Hydrocracking and Hydrosulfurizing Reactors, The Japan Steel Works, Ltd., February, 1983.

[7] J. Welty, Fundamentals of Momentum, Heat and Mass Transfer, 3erd Edition, John Wiley and Sons, New York, 1984.

[8] J. RedDy and M. Rasmussen, Análisis Matemático Avanzado con Aplicaciones a Ingeniería y Ciencias, Editorial Limusa S.A., México, 1990, pp. 268-269.

[9] S.S. RAO, The Finite Elements Method in Engineering, Pergamon Press, Oxford, 1989, p. 643.

[10] D. GASKELL, Introduction to Metallurgical Thermodynamics, Scripta Publishing, Washington D. C., 1973. 